\title{
TRABALHO DECENTE: ANÁLISE SOB A PERSPECTIVA DO IMPERATIVO CATEGÓRICO PRÁTICO DE IMMANUEL KANT
}

\author{
Nágila de Jesus de Oliveira Quaresma ${ }^{1}$
}

\section{RESUMO:}

O artigo pretende demonstrar a aplicação dos ensinamentos morais de Kant, em específico, o imperativo categórico prático, na efetividade do trabalho decente. A força de trabalho do ser racional deve ser vista como um fim em si mesma e, não, um mero instrumento. Necessária a mudança de perspectiva, o abandono do olhar servil para alcançarmos a valorização da mão de obra utilizada indispensável na cadeia produtiva. O problema de pesquisa consiste em identificar como os ensinamentos de Kant, mormente o imperativo categórico prático, é base para alcance do trabalho decente. Utilizamos como metodologia a análise teórica, além da pesquisa analítica.

Palavras-chave: Trabalho Decente. Imperativo Categórico Prático. Moral Kantiana. Valorização Profissional.

\section{DECENT WORK: ANALYSIS UNDER THE PERSPECTIVE OF IMMANUEL KANT'S PRACTICAL CATEGORY IMPERATIVE}

\begin{abstract}
:
The article aims to demonstrate the application of Kant's moral teachings, especially the practical categorical imperative, in the effectiveness of decent work. The workforce of the rational being must be seen as an end in itself and not a mere instrument. It is necessary to change the perspective, the abandonment of the servile gaze to reach the valorization of the indispensable used labor in the productive chain. The research problem is to identify how Kant's teachings, the practical categorical imperative, are the basis for the achievement of decent work. We use as methodology the theoretical analysis, besides the analytical research.
\end{abstract}

Keywords: Decent Work. Practical Categorical Imperative. Kantian Morality. Professional Appreciation.

\section{INTRODUÇÃO}

Immanuel Kant, filósofo prussiano do século XVIII, representou uma mudança de paradigma na conceituação e fixação do princípio da moralidade. Não apenas pela priorização do aspecto racional, a "razão pura", em terminologia do próprio autor (KANT, 2011, p. 18),

\footnotetext{
${ }^{1}$ Mestranda em Direito, Políticas Públicas e Direitos Humanos pelo Centro Universitário do Estado do Pará (CESUPA). Graduada em Direito pela Universidade Federal do Pará (UFPA), Integrante do Grupo de Pesquisa em Trabalho Decente (CESUPA) e da linha de pesquisa "Teorias da Justiça e Políticas Públicas: Fundamentação" (CESUPA/CNPq), Juíza do Trabalho do Tribunal Regional do Trabalho da $8^{a}$ região, e-mail: nagiladejesus@icloud.com .
} 
mas pela inovação na separação da vontade de Deus (a transcendência) com os pressupostos morais por si apresentados.

Além das peculiaridades ora apontadas, Kant busca a valorização do ser racional ou, para utilizar uma expressão contemporânea, do ser humano. A partir de então, apresenta fórmulas com o objetivo de provar a existência e aplicação prática dos postulados que acredita serem os corretos para alcance do princípio supremo da moralidade.

Os princípios ou fórmulas apresentadas denominou, em sua obra Fundamentação da Metafísica dos Costumes (KANT, 2011, p. 52), imperativos, dividindo-os em hipotéticos e categóricos, estes com enfoque substancialmente na valorização de si e do outro, pregando a rejeição da utilização de si ou de outrem meramente como meio ou instrumento. O cerne do pensamento kantiano é a convicção da imprescindibilidade de ações necessárias, universais e que priorize a humanidade. Um ato incondicional, em contraste, com os imperativos hipotéticos que são sempre condicionais e usam a razão apenas como instrumento dos objetivos pretendidos.

Kant infere que podemos conceituar e provar a existência do imperativo categórico em decorrência da imposição da primazia da humanidade do indivíduo como um fim em si mesmo, ou seja, pela simples existência como pessoa. Pelos mesmos fundamentos, não poderia estar a mercê de inclinações ou experiências individuais. Se assim o fosse, seria um meio para projetos ou anseios particulares, jamais um fim independente (KANT, 2011, p. 73).

Acrescenta postulados importantes em sua trajetória para alcançar a primazia da humanidade, ressaltando a autonomia da vontade e a indispensabilidade da liberdade para efetivá-la. Nesse invólucro, Kant nos apresenta o reino dos fins, no qual as coisas ou tem valor ou tem preço. Informa que, quando estão acima de quaisquer preços e não permitem equivalentes, possuem dignidade (KANT, 2011, p. 80).

Nessa esteira, em virtude da autonomia e liberdade que nos é conferida por sermos racionais e estarmos acima de qualquer preço, temos o direito de sermos tratados como fins, com respeito, ainda que fazendo parte de uma cadeia produtiva e sob a égide do modo de produção capitalista.

Assim, abrigados na universalidade típica do imperativo categórico e na noção de dignidade kantiana, procuraremos apreender a importância e incondicionalidade do direito ao trabalho decente aos trabalhadores.

O problema de pesquisa consiste em identificar como os ensinamentos de Kant, 
mormente o imperativo categórico prático, é base para alcance do trabalho decente. Utilizamos como metodologia a análise teórica, além da pesquisa analítica.

\section{A ESSÊNCIA DA MORALIDADE KANTIANA}

O conceito de moralidade para Kant está fundado, essencialmente, na ideia de racionalidade e abandono de quaisquer critérios empíricos. Rejeita por absoluto o envolvimento das inclinações, contingências como integrantes do conceito de moral pura. Ensina, para tanto, que devemos agir por dever, ou seja, restringindo nossas ações em conformidade com a lei moral proveniente unicamente da razão (KANT, 2011, p. 29).

Para Kant devemos fazer a coisa certa pelo motivo correto, independente das consequências. O que confere valor moral a determinada ação é sua motivação e não o que dela resulta. Ela é boa por si mesma.

Se agirmos por qualquer outro motivo que não seja o dever, como o interesse próprio, por exemplo, nossa ação não terá valor moral. Isso se aplica [...] não apenas ao nosso interesse próprio, mas também a qualquer tentativa de satisfazer nossas vontades e preferências, nossos desejos e apetites. Kant compara motivos como esses - que denomina "motivos de inclinação" com a motivação pelo dever. E insiste no fato de que apenas as ações motivadas pelo dever tem valor moral ( SANDEL, 2017, p. 144).

Acrescenta que os princípios morais devem ser classificados como juízos a priori, pois destituídos de qualquer envolvimento empírico, dada a necessidade de buscar conceitos necessários e universais, jamais encontrados na experiência particular de cada indivíduo ou em determinado momento histórico (KANT, 2011, p. 16).

Essa concepção vai de encontro com o pensamento de filósofos como David Hume, cuja teoria da moralidade foi duramente criticada por Kant, mormente pela base empirista da doutrina:

Como a moral, portanto, tem uma influência sobre as ações e os afetos, segue-se que não pode ser derivada da razão, porque a razão sozinha, como já provamos, nunca poderia ter tal influência. A moral desperta paixões, e produz ou impede ações. A razão por si só, é inteiramente impotente quanto a esse aspecto. As regras da moral, portanto, não são conclusões de nossa razão (HUME, 2001, p. 497).

Da mesma forma, o filósofo prussiano rejeita o utilitarismo como doutrina moral a ser utilizada como padrão da sociedade, quer em virtude de as considerar instrumentais, quer pela 
discordância quanto a busca da felicidade como bem maior.

Se os valores são associados às inclinações subjetivas, sustenta Kant, ainda que sob a forma genérica de "felicidade", eles não são (por isso mesmo) definidos pela razão, e, se os homens deixam-se orientar por eles, não são livres[...] Além disso, a moral utilitarista é incompatível com a justiça[...] A definição empírica, e portanto arbitrária, do que seja bom ou mau para os homens, leva a uma situação em que aqueles que têm o poder de impor tal definição oprimem os que dela discordam. Compreende-se também que, definido o que é "bom" e o que é "mau" por aqueles que têm o poder de fazê-lo, tudo o mais, e em particular a ordem jurídica, torna-se instrumento dos valores adotados (WEFFORT, 1999, p. 53).

Como já mencionado, Kant caminha em sentido oposto, em busca da universalidade e, consequente, eliminação das contingências na elaboração do conceito moral, sendo este o ponto central de sua formulação na busca da justificação do princípio supremo da moralidade. Nesse contexto, determinada máxima deve se converter em lei universal, livre de desejos pessoais, para que possa ser aplicada de forma incondicional e de modo a preservar o respeito ao próximo e a si mesmo.

Nessa esteira, o conteúdo das balizas morais pressupõe a existência de diretrizes que determinam o que deve ser feito de forma incondicional, segundo leis necessárias e universais. A esses comandos ou princípios práticos denominou imperativos, diferenciandoos, porém, do que chamou máximas.

As máximas são princípios práticos que valem somente para os sujeitos que as propõem, mas não para todos os homens, sendo portanto subjetivas(...) já os "imperativos, ao contrário, são princípios práticos objetivos, isto é, válido para todos. Os imperativos são "mandamentos" ou "deveres", ou seja, regras que expressam a necessidade objetiva da ação, o que significa que "se a razão determinasse completamente a vontade, a ação ocorreria inevitavelmente segundo tal regra"(ao passo que de fato, a intervenção de fatores emocionais e empíricos podem desviar-e, frequentemente desviam- a vontade dessa regra). (REALE, 1990, p. 908-909)

Kant avançou, delimitou e classificou seu objeto de estudo em imperativos hipotéticos e categóricos.

Ora, todos os imperativos ordenam hipotética ou categoricamente. Os hipotéticos representam a necessidade prática de uma ação possível como meio de alcançar qualquer outra coisa que se quer (ou que é possível que se queira). $\mathrm{O}$ imperativo categórico seria aquele que nos representasse uma acção como objectivamente necessária por si mesma, sem relação com qualquer outra finalidade.(Kant, 2011, p. 52). 
Nas claras palavras de Reale, a distinção ocorre da seguinte forma:

a) São "imperativos hipotéticos" quando determinam a vontade só sob condição de que ela queira alcançar determinados objetivos. Por exemplo, “ se quiseres passar de ano, deves estudar'[...] Esses imperativos só valem na condição de que se queira o objetivo para o qual estão voltados, por isso são "hipotéticos"(valem na "hipótese de que" se queira tal fim), mas valem objetivamente para todos aqueles que se propõem aquele fim. $\mathrm{O}$ ter ou não ter o desejo de alcançar aquele fim é uma questão remetida ao agente: portanto, a sua "imperatividade", ou seja, a sua necessidade, é condicionada. [...]

b) Já quando o imperativo determina a vontade não tendo em vista obter determinado efeito desejado, mas simplesmente como vontade, prescindindo dos efeitos que possa obter, então, temos o "imperativo categórico". O imperativo categórico, portanto, não diz " se quiseres...deves", mas sim "deves porque deves" ou "deves e pronto." (REALE, 1990, p. 909).

Os imperativos, portanto, quaisquer que sejam, emanam ordens e são frutos de uma vontade boa, que nada mais é que a obediência estrita à lei moral. Diferenciam-se no modo como a vontade é aguilhoada. Caso sejam resultantes de uma ação boa que será apenas um meio para alcançar qualquer outra finalidade, estar-se-á diante de um imperativo hipotético. No entanto, se a ação é boa em si mesma, sem quaisquer instrumentalização, configurar-se-á o imperativo categórico.

Os imperativos hipotéticos, por seu turno, podem ser subdivididos em regras de habilidade (voltados para objetivos determinados) e conselhos de prudência( abrangendo objetivos gerais, a exemplo da busca da felicidade).

Atinente ao imperativo categórico, sua apresentação pelo autor deu-se através de fórmulas, a serem seguidas por dever de obediência ao princípio da moralidade. Ei-las: fórmula da universalidade, da humanidade e da autonomia da vontade que serão melhor esclarecidas no tópico seguinte.

Essas considerações primordiais já nos situam, de plano, nos pilares da ética kantiana, baseada na imprescindibilidade da razão, sem qual não se pode falar de moral, quiçá moral pura; a necessidade da motivação das ações por dever (e não apenas por inclinações), bem como a firme rejeição das contingências e experiências na busca do princípio supremo da moralidade, capaz de conceder autonomia e liberdade ao seres humanos.

\section{IMPERATIVO CATEGÓRICO}

O imperativo categórico é a base da construção filosófica sobre moralidade de 
Immanuel Kant. Não por outro motivo, em grande parte do livro Fundamentação da Metafísica dos Costumes, o autor busca comprovar a existência e aplicação prática de sua formulação e, assim, o justifica de diversas maneiras, em nítida relação dialética de criatura e criador.

O imperativo categórico é externalizado de diversas formas, todas em busca da aplicação universal e incondicional dos princípios morais e, portanto, libertas dos equívocos que a experiência pode imprimir.

Como ponto inicial na árdua jornada de comprovar a existência do imperativo categórico e de reconhecer o melhor caminho para a busca da moralidade pura, o filósofo prussiano apresenta sua fórmula da universalidade expressa na ideia de que a ação, para ter validade moral, deve ser erigida a lei universal. Vejamos: “O imperativo categórico é portanto só um único, que é este: Age apenas segundo uma máxima tal que possas ao mesmo tempo querer que ela se torne lei universal” (KANT, 2011, p. 62).

Em outras palavras: "Age como se a máxima da tua acção se devesse tornar, pela tua vontade, em lei universal da natureza" (KANT, 2011, p. 62).

Assim, uma ação é moralmente válida quando pode ser aferida de maneira universal, sem particularismos, paixões, contingências e, ainda, desvinculada de determinado momento histórico.

A chancela moral é concedida, por conseguinte, justamente quando a ação é destituída das inclinações, do individualismo e da experiência.

Desconsidera-se como ação moral até mesmo quando praticada exclusivamente por temor, seja da sociedade, seja de Deus. Poder-se-ia exemplificar a ação decorrente exclusivamente por temor da crítica da sociedade ou do castigo divino. Kant, a esses comportamentos, não outorga a comenda meritória de agir "por dever", restringindo-os ao patamar inferior de agir "conforme o dever".

Salutares as colocações de CAYGILL (CAYGILL, 2000, p. 97-98), quanto a agir por ou conforme o dever: "Kant baseia a moralidade na intenção, pois embora seja possível agir de acordo com o dever com máximas determinadas por inclinação, a ação moral resulta unicamente do dever, isto é, de acordo com máximas em harmonia com a lei”.

Feitos esses esclarecimentos, Kant avança em sua missão primordial de provar a existência de sua criação, acrescentando-lhe fundamento prático. Apresenta-nos, então, a fórmula da humanidade, chamada de imperativo categórico prático, que, sem dúvida, é o 
ponto central de sua teoria moral no mundo dos fatos e transmudou a maneira de se direcionar o olhar para o ser humano, além de impactar, até os dias atuais, diversos avanços civilizatórios da sociedade contemporânea, o respeito a si mesmo e ao próximo, como baliza a ser seguida. Ei-lo : "Age de tal maneira que uses a humanidade, tanto na tua pessoa como na pessoa de qualquer outro, sempre e simultaneamente como fim e nunca simplesmente como meio" (KANT, 2011, p. 73).

A base do imperativo categórico, sem dúvida é o repúdio de conceder tratamento, quer a nós mesmos, quer aos outros como facilitador ou "simples meios" do que se pretende. Ao inverso, propugna reconhecermos a todos como fins em si.

$\mathrm{O}$ que seria um fim em si mesmo?

Consequentemente, um ser racional poderia se caracterizar como fim em si mesmo já através do fato de que ele pode racionalmente estabelecer fins e os perseguir; ou um ser racional poderia ser fim em si mesmo porque pode agir autonomamente. Qual é a posição de Kant? Ele afirma expressamente que todo homem e todo ser racional precisam entender sua existência necessariamente como 'fim em se mesmo'[...] o argumento é desenvolvido aproximadamente deste modo: já em sua propriedade de poder conhecer coisas e julgar, o homem precisa se compreender como ser espontâneo e livre, porque o juízo de que não se é livre no pensar e no julgar, ele mesmo aparece e necessita aparecer como um juízo fundamentado e com isso livre(e por isso autocontraditório) Como um tal ser pensante, o homem compreende-se enquanto inteligência e com isso como parte do mundo inteligível, e com base na unidade da razão teórica e prática ele se entende, ao mesmo tempo, como um ser livre em sentido prático (SCHONECKER E WOOD, 2014, p. 132-133)

Nós, os seres racionais ou, usando uma terminologia mais contemporânea, nós, os seremos humanos, somos "o" fim em si.

No que pertine à instrumentalização combatida, não se inclui nesse particular a utilização de determinada pessoa como meio para alcançar um fim de que seja indispensável na busca de um bem lícito, como o uso de conhecimentos médicos em busca da cura de enfermidades ou a contratação de um advogado para atuar em determinado processo jurídico.

A aversão aqui tratada é a utilização, quer de nós mesmos, quer de outrem como um mero instrumento, sem respeito, com o aspecto da descartabilidade, desconsiderando por completo o valor próprio peculiar a cada ser humano.

Nessa perspectiva, para alcance do imperativo prático é necessário que a vontade própria de cada um seja concebida como legisladora universal, pois se existe um imperativo categórico prático ele só pode ordenar de acordo com uma máxima que ao mesmo tempo 
possa ter a si mesma por objeto e seja legisladora universal.

A terceira fórmula prática:

Nunca praticar uma acção senão em acordo em acordo com uma máxima que se saiba poder ser uma lei universal, quer dizer só de tal maneira que a vontade pela sua máxima se possa considerar a si mesma ao mesmo tempo como legisladora universal. (KANT, 2011, p. 81).

A esse princípio, Kant denomina autonomia da vontade e sustenta ser a maneira única de encontrarmos postulados incondicionais, destituídos de quaisquer interesses fundantes e, consequentemente, outorgar-lhes o título da moralidade.

Portanto, olhar o outro e a nós como fins, só é possível com autonomia da vontade que simultaneamente cria a lei moral e a ela obedece. Não é fruto de coação de terceiros, ao contrário decorre da liberdade inerente a todos que somos racionais.

A vontade é um tipo de causalidade que pertence aos seres vivos enquanto racionais. A liberdade, então, seria a propriedade pela qual essa causalidade pode operar independentemente de determinação por causas externas. Da mesma forma, a necessidade natural é uma propriedade de que caracteriza a causalidade de todos os seres não-racionais, ou seja, a propriedade de serem eles determinados à atividade pela influência de causas externas [...] $\mathrm{O}$ conceito de causalidade implica o de leis segundo as quais, devido a algo que chamamos causa, uma outra coias, a que chamamos efeito, tem de ser posta [...] Que outra coisas pode ser a autonomia da vontade, então, senão, autonomia, isto é,a propriedade da vontade de ser lei para si própria? Contudo, a proposição "a vontade é, em todas as suas ações, lei para si própria"expressa apenas o princípio de não agir segundo nenhuma outra máxima senão aquela que possa ter-se a si própria como objeto, enquanto uma lei universal. Esta é precisamente a fórmula do imperativo categórico e o princípio da moralidade. Assim, uma vontade livre e uma vontade subordinada são uma e a mesma coisa. (WEFFORT, 1999, p. 99).

Portanto, nessa junção perfeita de universalidade, humanidade, autonomia da vontade e liberdade, tudo o que se afasta dos seus respectivos postulados, em outro viés, tudo o que busca a instrumentalização de si ou dos outros, além de por óbvio não passar no teste da moralidade, fere a integridade e dignidade pretendidas pelo do reino dos fins.

Por esta palavra reino entendo eu a ligação sistemática de vário seres racionais por meio de leis comuns [...] Os seres racionais estão pois todos submetido a esta lei que manda que cada um deles jamais se trate a si mesmo ou aos outros simplesmente como meios, mas sempre simultaneamente como fins em si [...] Mas um ser racional pertence ao reino dos fins como seu membro quando é nele em verdade legislador universal, estando porém também submetido a estas leis [...] A moralidade consiste pois na relação de toda a acção com a legislação, através da qual somente se torna possível um reino dos fins[...]. (KANT, 2011, p. 80-81). 
Exatamente no reino dos fins que Kant projeta com excelência o ser racional, reconhecendo e elevando-o a um patamar tal que, desde então até os dias atuais, empresta-se atenção aos seus valores, repercutindo com vigor no tratamento interpessoal, nas legislações e políticas públicas enunciadas. Não há como conceber um ordenamento jurídico justo e, consequentemente, o direito de todos ao trabalho decente, sem olhar para o postulado básico proposto no reino dos fins:

No reino dos fins tudo tem ou um preço ou uma dignidade. Quando uma coisa tem um preço, pode-se pôr em vez dela qualquer outra coisa como equivalente; mas quando uma coisa está acima de todo o preço, e portanto não permite equivalente, então tem ela dignidade.

$\mathrm{O}$ que se relaciona com as inclinações e necessidades gerais do homem tem um preço venal; aquilo que, mesmo sem pressupor uma necessidade, é conforme a um certo gosto, isto é a uma satisfação no jogo livre e sem finalidade das nossas faculdades anímicas, tem um preço de afeição ou de sentimento[...]; aquilo porém que constitui a condição só graças a qual qualquer coisa pode ser um fim em si mesma, não tem somente um valor relativo, isto é um preço, mas um valor íntimo, isto é dignidade. (KANT, 2011, p. 82).

É justamente a presença da dignidade, intrínseca aos seres humanos, que vai ampliar ou alterar por completo a visão reducionista de direitos, espraiando a todos a necessidade de conceder o devido valor ao próximo e a si, pelo simples fato de sermos um fim em nós mesmos, independente de credo, raça ou escolhas pessoais, estas claros que não afetem negativamente a coletividade.

O avanço dos estudos sobre direitos humanos tem em Kant um de seus precursores. Michael Sandel afirma que “A importância atribuída por Kant à dignidade humana define nossas concepções atuais dos direitos humanos universais. Ademais, seu conceito de liberdade figura em muito de nossos debates contemporâneos sobre justiça.” (SANDEL, 2017, p. 137).

Sabe-se que para Kant liberdade não implica ausência de empecilhos para a pratica de determinado ato. Agindo assim, não passamos de escravos de nossos desejos.

Ser livre para Kant é agir com autonomia, de acordo com a lei que o próprio agente cria e se impõe a si mesmo, porém em obediência ao dever e de aplicabilidade universal, indispensável na conferência de respeito a todos os seres humanos, indistintamente, por serem fins em si mesmos.

Por outra vertente, agimos em oposição à autonomia, quando praticamos o que Kant 
nominou heteronomia, ou seja, "quando agimos de maneira heteronômica, agimos em função de finalidade externas. Nós somos os instrumentos e não o autores, dos objetivos que tentamos alcançar (SANDEL, 2017, p. 142).

BRITO FILHO, porém, alerta:

Ao se indicar a razão, a autonomia que tem o ser humano de fazer as suas escolhas, todavia, aparentemente é possível entrar em uma armadilha, pois, como nem todos os seres humanos são dotados de razão e consciência, aparentemente seria possível dizer que a dignidade não é atributo de todos os seres humanos, ou, por outro lado, que esse não é o fundamento que garantiria de forma universal a dignidade e, por via de consequência, os Direitos Humanos.

Não, porque a razão, aqui, deve ser entendida de forma potencial, com uma dupla face" (BRITO FILHO, 2018, p. 48).

Ou seja, a autonomia deve ser considerada em abstrato, potencialmente, a fim de espraiar a dignidade a todos os seres humanos e não apenas os racionais. A propósito, a dignidade é o fundamento dos direitos mais básicos e importantes do homem. É a partir dela e de toda a construção kantiana que envolve seu conceito, mormente a existência e aplicabilidade do imperativo categórico prático, incondicional e universal, que nos é atribuída a incumbência de olhar a cada um de nós como fins em si.

Embora não conceituando claramente o que seja dignidade, Kant indica os pressupostos que conduzem a seu alcance, bem como aponta o caminho de sua objeção .

Segundo, embora não tenha indicado o que é, concretamente, a dignidade, Kant demarcou claramente seu espaço, ao colocar, em sua oposição, o preço. Assim, respeita-se a dignidade do ser racional quando não se pratica atos que possam incliná-lo (o ser racional) em direção a atributo que não possui: o preço, ou seja, instrumentalizá-lo. Concretamente,isso ocorre quando se respeitam direitos básicos do ser racional, como diria Kant, ou do ser humano, como se diz agora, e esses direitos básicos, por óbvio, constituem o que se denomina de Direitos Humanos, daí a natural relação entre estes e a dignidade, justificando que esta seja o seu fundamento (BRITO FILHO, 2018, p. 49-50).

A cada um é dada a particularidade inconfundível de valor não mensurável pelo simples fato de possuir condição humana. Não podemos ser trocados pelo equivalente. Não há como substituir o "Pedro" pelo "Marcelo", ainda que sejam gêmeos monozigóticos.

No entanto, não raro, quando se fala do mundo do trabalho, em que é transferida a força física ou intelectual de uns, decorrente da paga de determinada contraprestação, verifica-se a instrumentalização dessa força, a tentativa de uso como mercadoria, a descartabilidade sem garantia do mínimo que possa respeitar a dignidade dos envolvidos. 
A despeito dos ensinamentos Kantianos e progresso na busca da efetivação dos direitos humanos, nesses inclusos os dos trabalhadores, tem-se verificado com frequência o uso da força de trabalho, como mero instrumento na cadeia produtiva. A precarização da mão de obra, que já não era novidade, aumenta com as novas formas de pactuação entre empregados e empregadores, na esteira atual de flexibilização de trabalhistas. O que deveria causar repúdio é até banalizado ou visto da forma mais conveniente aos interesses envolvidos, utilizando-se de argumentos que pretendam chancelar condutas, muitas vezes utilizando do próprio ordenamento jurídico.

Nesse contexto, em conformidade com as premissas Kantianas, ora elucidadas, analisar-se-á a seguir, as formas de garantia do trabalho decente e como efetivá-lo, bem como o repúdio às contemporâneas práticas de instrumentalização da força de trabalho.

\section{TRABALHO DECENTE}

A única forma de trabalho possível nos dias atuais é o trabalho livre. Essa garantia, ainda que não satisfatória em diversas legislações, é presente basicamente em todos os ordenamentos jurídicos da atualidade.

No Brasil, inúmeros direitos trabalhistas, previstos na Consolidação das Leis Trabalhistas e em leis esparsas, foram elevados ao status constitucional em 1988, compondo, assim, os direitos sociais e econômicos, denominados de Direitos Humanos de segunda dimensão. Ou seja, os direitos mais comezinhos trabalhistas, aquilo que na expressão de Delgado, compõe o patamar civilizatório mínimo, foram albergados pela Constituição Federal de 1988 e, assim, fazem parte do conjunto dos direitos humanos.

Tais parcelas são aquelas imantadas por uma tutela de interesse público, por constituírem um patamar civilizatório mínimo que a sociedade democrática não concebe ver reduzido em qualquer segmento econômico-profissional, sob pena de se afrontarem a própria dignidade da pessoa humana e a valorização mínima deferível ao trabalho (arts. 1o, III, e 170, caput, CF/88)" (DELGẢDO, 2001, p. 97).

Da mesma forma, esses direitos mínimos dos trabalhadores estão previstos em inúmeros instrumentos internacionais, como as Convenções da Organização Internacional do Trabalho (OIT) e alguns tratados internacionais. Porém, dada a sua importância histórica e jurídica, destacam-se os artigos XXIII e XXIV da Declaração Universal do Direitos Humanos, como bom exemplo de direitos mínimos a serem protegidos:

Art. XXIII

1. Todo ser humano tem direito, à livre escolha de emprego, a condições justas e favoráveis de trabalho e à proteção contra o desemprego. 
2. Todo ser humano, sem qualquer distinção, tem direito a igual remuneração por igual trabalho.

3. Todo ser humano que trabalha tem direito a uma remuneração justa e satisfatória, que lhe assegure, assim como à sua família, uma existência compatível com a dignidade humana e a que se acrescentarão, se necessário, outros meios de proteção social.

4. Todo ser humano tem direito a organizar sindicatos e a neles ingressar para proteção de seus interesses.

Art. XXIV

Todo ser humano tem direito a repouso e lazer, inclusive a limitação razoável das horas de trabalho e as férias remuneradas periódicas.

Os artigos supra transcritos não abarcaram alguns direitos posteriormente consagrados e que, sem dúvida, atualmente compõem o conjunto mínimo de direitos do trabalhador subordinado, o empregado, a serem preservados para efetivação da dignidade, mormente em sua versão sócio-laborativa. BRITO FILHO esclarece a amplitude de direitos não tratados nos artigos mencionados:

Esse rol, observa-se, não esgota o conjunto do que poderíamos denominar de direitos mínimos do homem-trabalhador . Não inclui expressamente, por exemplo, o direito ao trabalho que preserve a saúde do trabalhador e que possa ser prestado com segurança. Não trata, de forma direta, do direito ao tratamento igualitário entre os diversos postulantes a um trabalho, ou ocupantes de emprego, embora haja a garantia genérica no art. II. Fornece, entretanto, a ideia básica do que é o conjunto mínimo de direitos dos trabalhadores (BRITO FILHO, 2018, p. 47).

Por outro lado, o conceito de trabalho decente desenvolvido pela OIT (Organização Internacional do Trabalho) em 1999 e que sintetiza a missão histórica da instituição, conforme consta em sua página oficial na rede mundial de internet, consiste em:

promover oportunidades para que homens e mulheres obtenham um trabalho produtivo e de qualidade, em condições de liberdade, equidade, segurança e dignidades humanas, sendo considerado condição fundamental para a superação da pobreza, a redução das desigualdades sociais, a garantia da governabilidade democrática eu desenvolvimento sustentável.

No site, a OIT a importância da matéria reflete-se na assertiva que o trabalho decente é o ponto de convergência dos quatro objetivos estratégicos da instituição:

1. o respeito aos direitos no trabalho, especialmente aqueles definidos como fundamentais(liberdade sindical, direito de negociação coletiva, eliminação de todas as formas de discriminação em matéria de emprego e ocupação e erradicação de todas as formas de trabalho forçado e trabalho infantil); 
2. a promoção do emprego produtivo e de qualidade;

3. a ampliação da proteção social;

4. e o fortalecimento do diálogo social

Percebe-se no conceito de trabalho decente informado pela OIT que o pressuposto primordial é o respeito ao indivíduo, por ser um fim em si mesmo, por seu valor insubstituível e sua dignidade. É um imperativo e como tal deve ser observado por todos, independente dos interesses particulares de cada um.

Não há como anuir que, embora seja necessário colocar a disposição de seu empregador sua força de trabalho, muitas vezes o único bem que possui, o trabalhador seja submetido a horas extenuantes de trabalho, a supressão de intervalo, ao assédio, enfim, a condições indignas que inviabilize a realização dos direitos básicos do homem. A título de exemplo fazemos a seguinte indagação: poder-se-ia afirmar que é decente um emprego cuja jornada diária, com frequência, ultrapasse às 12 horas, ainda que devidamente registrada nos controles de ponto e seja satisfatoriamente remunerado? Este trabalhador teria convívio social e familiar? Como ficaria sua saúde? Quais as possibilidades de ser vítima de acidente de trabalho e ter precocemente sua vida ceifada?

É da essência do direito do trabalho, desde seu nascedouro, a proteção ao trabalhador que, despossuído de capital, vende sua força de trabalho e, para tanto, é basilar a prestação de serviços em condições que lhes assegurem tratamento com respeito e não como meros instrumentos à disposição dos detentores de capital. Nesse contexto, deve ser garantida remuneração justa, limite de jornada, direito de associação, concessão de repouso, meio ambiente de trabalho hígido, enfim todo o conjunto de direitos que culmine no trabalho digno.

BRITO FILHO, em sua obra Trabalho Decente (2018), aprofundou o que entende como conjunto mínimo de direitos do trabalhador indispensáveis para caracterização do trabalho decente, o qual seria dividido de acordo com plano a ser considerado, sendo no plano individual: Direito ao trabalho, Liberdade de escolha do trabalho, Igualdade de oportunidades para e no exercício do trabalho, Direito de exercer o trabalho em condições que preservem a saúde do trabalhador, Direito a uma justa remuneração, Direito a justas condições de trabalho, principalmente limitação da jornada de trabalho e existência de períodos de repouso e Proibição do trabalho infantil. Já no plano coletivo, a Liberdade sindical e no plano da seguridade, a Proteção contra o desemprego e outros riscos sociais. Assim,

[...] esses direitos mínimos do homem-trabalhador é que devem caracterizar

o que denominamos trabalho decente. Menos que isso é sujeitar o 
trabalhador a condições de trabalho que estão abaixo do necessário para que seja preservada sua dignidade [...]

Negar o trabalho nessas condições, dessa feita, é negar os Direitos Humanos do trabalhador e, portanto, atuar em oposição aos princípios básicos que os regem, principalmente o maior deles, a dignidade da pessoa humana[...] (BRITO FILHO, 2018, p. 57).

Não obstante, embora haja previsão legislativa e constitucional, reconhecendo o mínimo de direitos ao empregado subordinado, nos mais variados ordenamentos jurídicos atuais, no plano fático, vemos com frequência descumprimento dos basilares direitos trabalhistas, alguns chegando até mesmo à criminalidade, como nos casos de trabalho em condições análogas de escravo.

A distância entre o que prescreve o texto legislativo e a concretização dos direitos, é comum no ordenamento jurídico brasileiro, embora, nos últimos anos, a própria legislação, a exemplo da Lei n. 13.467 de 2017, chamada de reforma trabalhista, tem se incumbido de eliminar direitos, como as horas de percurso e introduzir novas figuras jurídicas, como o trabalho intermitente (art. 452- A da Consolidação das Leis Trabalhistas) que, dispensando grandes teorizações, promove a precarização da mão de obra ou quiçá seu uso como mero instrumento.

Sem proteção aos direitos básicos dos trabalhadores, não há falar em preservação da dignidade no mundo do trabalho. Não há dúvidas que, no campo da concretização dos direitos fundamentais, precisamos evoluir, embora a CLT tenha 76 anos e a Constituição Federal três décadas de publicação, muitos direitos não foram efetivados e outros sequer regulamentados, como a proibição da despedida arbitrária prevista no art. $7^{\circ}$, inciso I da CF/88.

No caminho perigoso da inefetividade dos direitos mínimos trabalhistas, surge a real possibilidade do trabalho indigno. Este seria representado, nas palavras de BRITO FILHO, pelo "trabalho em condição análoga à de escravo; o trabalho com discriminação e/ou exclusão; o trabalho infantil; e o trabalho intermediado" (BRITO FILHO, 2018, p. 87).

Embora não faça parte do objetivo da presente pesquisa descer as minúcias de cada conceito sobre as formas de trabalho indigno, elas representam com clareza a desconstrução da dignidade do trabalhador, a instrumentalização do ser humano, o uso da força de trabalho como simples meio, não raro, para fins perversos e a atribuição de um preço, sempre baixo.

A aversão à mercantilização da mão de obra e tudo que impeça a efetividade do arcabouço dos direitos mínimos garantidos é medida de ordem, sem a qual não se pode falar em dignidade e Estado Democrático de Direito. É a busca pela presença do imperativo 
categórico prático no mundo do trabalho que tem como um de seus princípios a autonomia da vontade, apenas realizável com a liberdade também na seara trabalhista.

A utilização da força de trabalho de forma abusiva é antítese e aversão aos conceitos de liberdade e dignidade, sem os quais não se pode falar em trabalho decente e digno, muito menos em justiça social. Os pressupostos são umbilicalmente ligados. O imperativo prático é chave para mudar o curso da história de forte influência escravocrata que nos acompanha, mudando o paradigma para que se trate o outro com respeito e consideração, um fim em sim mesmo, ainda que sua mão de obra esteja à disposição de outrem.

Os integrantes do reino dos fins tem um significativo valor e não são meros equivalentes. Por conseguinte, não são trocados por bens materiais, ainda que saibamos que o objetivo do modo de produção capitalista, que estamos inseridos, seja o aumento do lucro e diminuição dos custos. Porém, é necessário buscar recursos que contenha a agressividade do capital e preserve a dignidade dos trabalhadores e, nessa esteira, o respeito ao conceito de trabalho decente ampliativo, proposto por BRITO FILHO é medida que se impõe.

Assim, a visão que deve ser emprestada aos trabalhadores, moradores do reino dos fins e dignos de decência no labor, é a que esteja em sintonia com a autonomia da vontade e a presença da liberdade.

A liberdade(a independência em relação ao arbítrio coercitivo de um outro), na medida em que possa coexistir com a liberdade de qualquer outro segundo uma lei universal, é esse direito único, originário, que cabe a todo homem em virtude de sua humanidade (KANT, 2013, p. 43-44).

A liberdade é inerente a dignidade e, esta, é pressuposto da garantia e implementação dos comezinhos direitos, os denominados direitos humanos, inclusos nestes os de caráter trabalhista. Falar em trabalho decente pressupõe o respeito a força de trabalho do ser humano que mesmo dispondo de sua mão de obra para manter a sobrevivência, não passa a ser um mero instrumento, mantem a dignidade, acima de todo preço, por ser um fim em si mesmo, característica incondicional e universal da humanidade presente apenas no imperativo categórico.

\section{CONCLUSÃO}

Os avanços sociais ao longo dos anos, na busca pela preservação da dignidade no mundo do trabalho, são um fato. Evidente que nesse processo alguns erros foram cometidos e as arestas precisam ser cortadas. No entanto, é necessário aprimorar as conquistas, 
principalmente pelo abismo que por vezes encontramos entre a previsão legislativa e a efetivação desses direitos.

Não há como implementar o exercício do trabalho decente sem observar o exato valor de cada trabalhador, considerado como um fim em si mesmo e se afastar de artifícios que usam a força de trabalho como mero instrumento da cadeia produtiva na busca ávida pelo lucro. E, nesse particular, os ensinamentos de Kant são estritamente adequados. Falar em direitos básicos do trabalhador, direitos humanos sociais, sem fidelizar com o conceito de dignidade é retirar o próprio fundamento dos direitos invocados.

A partir do conceito kantiano de dignidade, livre de interesses particulares é que se imprime a decência no trabalho como imperativo. Para além da mudança de visão referente ao uso da mão de obra do trabalhador no modo de produção capitalista em busca meramente da diminuição dos custos, do aumento da produtividade e do lucro, são necessárias medidas que assegurem o respeito e garantam a efetividade dos direitos, de modo a equilibrar os interesses do capital e a preservação do trabalho decente.

O trabalhador é autor dos objetivos que pretende alcançar, possui finalidades próprias. Não é mero meio dos objetivos alheios. Embora, sua força de trabalho esteja à disposição de outrem, tal condição não retira sua liberdade, de modo justamente a preservar sua dignidade, diferenciando-o dos objetos, estes sim, passível de apropriação particular.

Assim, a mão de obra contratada não pode ser utilizada de forma arbitrária por essa ou aquela vontade, ainda que seja por quem as remunera. A justiça deve assegurar o direito e respeito a todos, bem como sua efetividade, de modo que a humanidade, vista como fim em si, seja realidade, quer no tratamento próprio, quer no tratamento dispensando a outrem, inclusive aos participantes do mercado de trabalho.

Como não bastasse, na contramão da efetividade dos direitos básicos trabalhistas, diversos ordenamentos jurídicos, a exemplo do Brasil (Lei n. 13.467/2017), implementaram reformas legislativas amparadas no discurso de retomada do crescimento econômico e aumento dos postos de trabalho. Discurso vazios, sem dados ao menos indicativos que a manutenção de algumas garantias trabalhistas seriam realmente causadora dos problemas socioeconômicos locais.

Embora recentes as alterações, as flexibilizações permitidas já apontam para o aumento da precarização da mão de obra e da desigualdade social, considerando que os salários diminuiriam e a instabilidade nos empregos aumentou. A não vedação ao retrocesso 
social ficou no plano das ideias. Por outro quadrante, na luta contra a desvalorização do trabalho e com o primordial objetivo de operacionalizar a concretização dos direitos humanos básicos do trabalhador é que urge a necessidade de implementação de políticas públicas no combate a toda e qualquer forma de trabalho indigno, o trabalho em condição análoga à de escravo, o trabalho com discriminação e/ou exclusão, o trabalho infantil e o trabalho intermediado. Ao contrário, tais políticas devem viabilizar, no campo dos fatos, o direito ao trabalho, para muitos um sonho, com a respectiva remuneração justa, independente de raça, sexo ou escolhas pessoais. Devem, ainda, garantir um meio de trabalho hígido, mormente por ser inconcebível que o mesmo trabalho que dignifica o homem, seja ao mesmo tempo um caminho para perda da vida.

Da mesma forma, não se pode olvidar do aspecto coletivo, que no Brasil anda a passos lentos, pois embora haja a garantia da liberdade sindical, a perversa unicidade sindical permanece inalterada e impede o avanço no particular. Por fim, a proteção em tempos de desemprego e outras possíveis intempéries sociais.

Assim, legislações adequadas e políticas públicas que juntas promovam esses direitos no campo da realidade e reconheçam o valor de cada homem como um fim em si mesmo, rejeitando o retrocesso, proporcionando condições dignas aos tralhadores na busca da construção de uma sociedade livre, justa e solidária, é a forma eficaz de ser compreender o direito ao trabalhado decente. Esta garantia é necessária e universal na preservação da humanidade e respectiva dignidade, em seu aspecto sócio laborativo. Eis o imperativo categórico prático no mundo do trabalho.

\section{REFERÊNCIAS}

BRASIL. Consolidação das Leis do Trabalho. Decreto $\mathrm{n}^{\circ} 5.452$, de $1^{\circ}$ de maio de 1943. Aprova a consolidação das leis do trabalho. Disponível em: http://www.planalto.gov.br/ccivil_03/decreto-lei/del5452.htm. Acesso 30 jan. 2019

BRITO FILHO, José Claudio Monteiro de. Direitos Humanos. 2 ed. São Paulo: LTr, 2018.

BRITO FILHO, José Claudio Monteiro de. Trabalho Decente. Análise jurídica da exploração do trabalho: trabalho escravo e outras formas de trabalho indigno. 5 ed.atual. de acordo com a reforma trabalhista. São Paulo: LTr, 2018.

CAYGILL, Howard. Dicionário Kant. Trad. Álvaro Cabral. Rio de Janeiro: Jorge Zahar. Editor, 2000. 
DELGADO, Maurício Godinho. Direito coletivo do trabalho e seus princípios informadores. $\begin{array}{llllllll}\text { Revista do TST. Brasília } & \text { v. } 1 & 67, & \mathrm{n} & \mathrm{B} 2, & \text { abr/jun } & 2001\end{array}$ https://juslaboris.tst.jus.br/bitstream/handle/20.500.12178/52335/007_delgado.pdf?sequence= 2\&isAllowed=y Acesso em 20 de ago. de 2019

FUNDO DAS NAÇÕES UNIDAS PARA A INFÂNCIA. DECLARAÇÃO UNIVERSAL DOS DIREITOSHUMANOS. Disponível https://www.unicef.org/brazil/pt/resources_10133.htm Acesso em 11 de jun. de 2018.

HUME, David. Tratado da natureza humana: uma tentativa de introduzir o método experimental de raciocínio nos assuntos morais. Tradução de Deborah Danowski. São Paulo: UNESP, 2001.

KANT, Immanuel. Fundamentação da Metafísica dos Costumes. Tradução de Paulo Quintela. Introdução de Pedro Galvão. Lisboa- Portugal: Edições 70, 2011.

KANT, Immanuel. Metafísica dos Costumes. Primeira Parte: Primeiros Princípios Metafísicos da Doutrina do Direito. [Trad. Clélia Ap. Martins], p. 9-178; Segunda Parte: Primeiros Princípios da Doutrina da Virtude. [Trad. Bruno Nadai, Diego Kosbiau e Monique Hulshof], p. 179-311. Petrópolis, RJ: Vozes; Bragança Paulista, SP: Editora Universitária São Francisco, 2013.

ORGANIZAÇÃO INTERNACIONAL DO TRABALHO. Trabalho Decente. http://www.ilo.org/brasilia/temas/trabalho-decente/lang--pt/index.htm Acesso em 11 de jun. de 2018.

REALE, Giovanni e DARIO, Antiseri. História da filosofia: Do humanismo a Kant. Vol. 2. São Paulo: Paulus, 1990.

SANDEL, Michael J. Justiça- o que é fazer a coisa certa. Tradução de Heloísa Matias e Maria Alice Máximo. Rio de Janeiro: Civilização Brasileira, 2011.

SCHONECKER, Dieter e WOOD, Allen. A "Fundamentação da metafísica dos costumes" de Kant: um comentário introdutório; tradução Robinson dos Santos e Gerson Neumann. São Paulo: Edições Lyola, 2014.

WEFFORT, Francisco C. (Org.). Os clássicos da política: Burke, Kant, Hegel, Tocqueville, Stuart Mill, Marx. 8. ed. São Paulo: Ática, 1999. v. 2. (Série Fundamentos; n. 63). 